\title{
SPACE CONFIGURATION AND NUMERICAL RELATIONSHIP DURING PROFESSIONAL SOCCER MATCHES: A PROPOSAL FOR SMALL-SIDED GAMES DESIGN
}

original paper

(1) University School of Physical Education in Wroclaw

DOI: https://doi.org/10.5114/hm.2018.83386

\author{
NICOLAU MELO DE SOUZA ${ }^{1}$, FABIO GIULIANO CAETANO ${ }^{1}$, \\ PAULO ROBERTO PEREIRA SANTIAGO ${ }^{2}$, SERGIO AUGUSTO CUNHA ${ }^{3}$, \\ RICARDO DA SILVA TORRES ${ }^{4}$, FELIPE ARRUDA MOURA ${ }^{1}$ \\ ${ }^{1}$ Sports Sciences Department, State University of Londrina, Londrina, Brazil \\ ${ }^{2}$ School of Physical Education and Sport of Ribeirao Preto, University of São Paulo, São Paulo, Brazil \\ ${ }^{3}$ College of Physical Education, University of Campinas, Campinas, Brazil \\ ${ }^{4}$ Institute of Computing, University of Campinas, Campinas, Brazil
}

\section{ABSTRACT}

Purpose. The purpose of this study was to analyse the most recurrent characteristics of soccer attacking sequences regarding the effective space available, the numerical relationship, and the distance between the defensive line and the goal.

Methods. Overall, 4 Brazilian professional matches were recorded and the trajectories of 101 players were obtained by a tracking method. The variables of the studies were: length (the distance between 2 more distant players, longitudinally), width (the distance between 2 more distant players, laterally), numerical relationship (the number of attacking players vs. the number of defending players inside a given area), and the distance to the goal (the distance between the defensive player closer the goal line and the goal line).

Results. The mean values and standard deviations were $24.59( \pm 13.40) \mathrm{m}$ for the length, $44.13( \pm 12.51) \mathrm{m}$ for the width, and $29.19( \pm 11.40) \mathrm{m}$ for the distance to goal line. A match was characterized mostly by the interaction among a large number of players $(p<0.001)$. The length, width, and distance to goal line changed depending on the numerical relationship. However, the effective space available was characterized by the width, being greater than the length, and the game had more situations of defensive numerical superiority, followed by the numerical equality $(p<0.001)$.

Conclusions. The study presented insights regarding strategies for soccer games that can guide coaches in the design of training drills in accordance with real situations in a soccer match.

Key words: match analysis, small-sided games, football, tactics, training, team sports

\section{Introduction}

Small-sided games (SSGs) are constantly used by coaches as part of a regular training program during the season, and are characterized by a reproduction of a soccer match but with a lower number of players, smaller effective space, and often different rules [1]. SSGs improve the physical, technical, and tactical dimension simultaneously [2]. Recently, studies have focused on the effects of different SGG formats and task conditions on changes in the physiological [1, 3-5], technical [3, 4, 6], physical [7, 8], and tactical performance $[4,6,9,10]$, on manipulating the space, the number of players, the number of ball touches per player [1, 4-7, 9-12], and on the impact of training programs involving SSGs [5, 12].

By analysing the space control during a match, many variables have been reported, such as length (the distance between the 2 more distant players, longitudinally, without goalkeepers), width (the distance between the 2 more distant players, laterally, without goalkeepers), the area (formed by the width and length),

Correspondence address: Nicolau Melo de Souza, Sports Sciences Department, State University of Londrina, Rodovia Celso Garcia Cid - Pr 445 Km 380 Campus Universitário, PR, 86057-970, Londrina, Brazil, e-mail: nicolaumelo@gmail.com

Received: September 30, 2018

Accepted for publication: January 28, 2019

Citation: de Souza NM, Caetano FG, Santiago PRP, Cunha SA, Torres RS, Moura FA. Space configuration and numerical relationship during professional soccer matches: a proposal for small-sided games design. Hum Mov. 2018;19(5)special/ issue:121-128; doi: https://doi.org/10.5114/hm.2018.83386. 
the numerical relationship (the number of attacking players vs. the number of defending players inside a given area), and individual playing area (IPA) (obtained by dividing the area among the players) [13-15].

With the purpose of better explaining the subgroups (interaction of given players, such as attackers and defenders closer to the ball) during a match, Gonçalves et al. [16] introduced the notion of an effective playing space (the smallest polygonal area delimited by the peripheral outfield players) for groups of 3-10 players. Aiming to design training drills with similar characteristics to playing spaces, Caro et al. [17] presented the length, width, and IPA considering the 4 and the 7 nearest players of both teams.

The SSG models described in literature usually involve the goalkeeper inside the designed area $[1,5,8$,
12]. However, during a match, there is an additional area between the goal line and the nearest defender, which is associated with the defence behaviour [13, 15]. Furthermore, the numerical relationship during a match was reported in the studies by Clemente et al. [18] and Vilar et al. [19].

The described studies provided important insights related to the tactical features of SSGs and official soccer matches. In addition, recent studies have shown that junior and senior players did not present differences in physiological responses or technical actions, proving that for SSG design, players are expected to behave in a similar manner, regardless of the level [3]. However, when planning SSG protocols, the choice of the area of play and the number of players involved were arbitrary defined in most of the studies. Usually, the

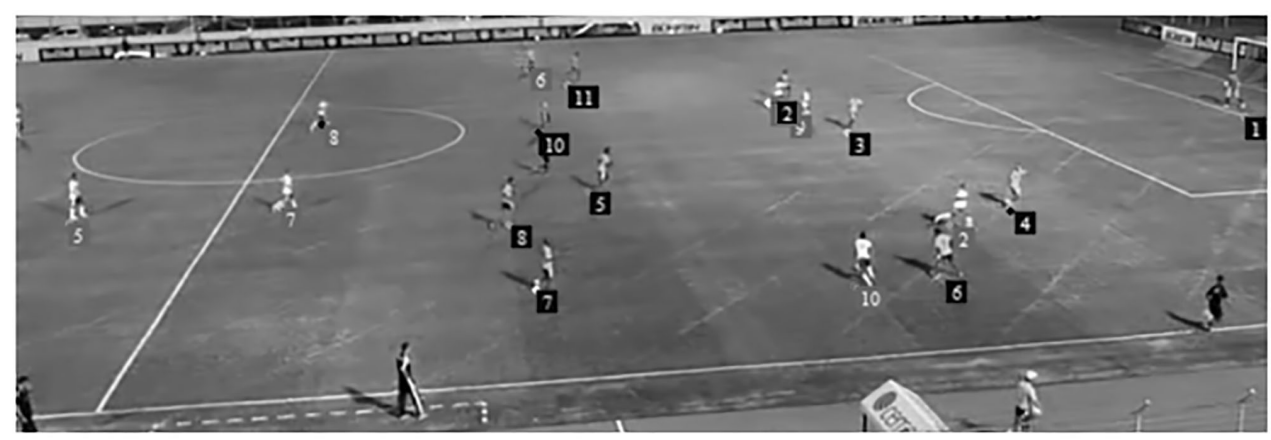

\section{Љ}

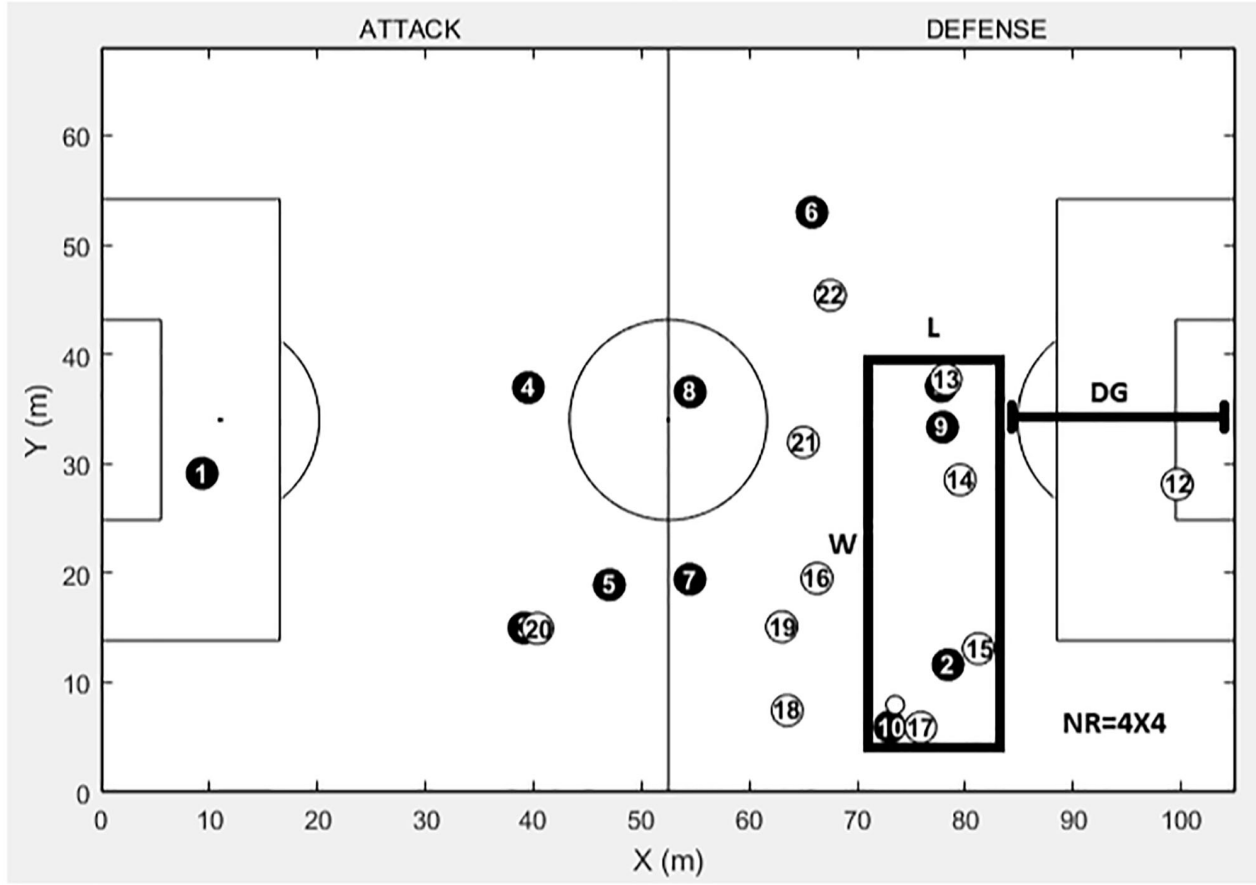

Figure 1. Procedures of data collection: players' position obtained after the tracking procedures, and a representation of the length (L), width (W), distance to goal line (DG) variables, and numerical relationship (NR) 
designs were not based on match analyses and were mainly with numerical equality, i.e., the number of attackers was the same as the number of defenders. Furthermore, during training sessions, coaches typically design rectangular areas that may differ from the effective playing space, usually represented by areas with more than one vertex. There is a need for a characterization of the playing space, defined by the values of length and width, the numerical relationship, and the distance of the defenders from goal line during official matches in order to provide insights for designing SGGs based on real match situations. Therefore, the purpose of this study was to analyse the most recurrent characteristics of soccer attacking sequences regarding the effective space available, the numerical relationship, and the distance between the defensive line and the goal.

\section{Material and methods}

\section{Participants}

The sample consisted of 101 professional Brazilian players from 5 different teams taking part in 4 matches of the 2014 Second Division of São Paulo State League. The matches were recorded in Campinas, São Paulo state, Brazil. The score difference ranged from 1 to 2 goals.

\section{Data collection procedures}

The matches were recorded by 4 digital cameras $(30 \mathrm{~Hz})$, positioned at the highest points of the stadiums, remaining static; each covered at least one quarter of the pitch. Before the matches, the coordinates of the specific points associated with the pitch coordinate system were obtained. After the games, the videos were transferred to a computer and the DVideo software was used to determine the corresponding projections of these points in the image. The homography parameters of the image-object transformation were calculated on the basis of the proposed direct linear transformation method [20], and the 2D coordinates of the players were reconstructed in relation to the pitch coordinate system. DVideo has an automatic tracking rate of $94 \%$ of the processed frames, an average error of $0.3 \mathrm{~m}$ for the determination of player position, and an average error of $1.4 \%$ for the distance. The trajectories were smoothed by a third-order Butterworth low-pass filter with a cut-off frequency of $0.4 \mathrm{~Hz}$, as previously reported [21].

The variables of the study were quantified frame by frame and analysed by each attacking sequence, defined as the interval between the first pass after a restart of play (i.e. goal kick, throw-in, free kick) until the ball was out of play. As illustrated in Figure 1, the variables analysed were: (1) the length, (2) the width, (3) the numerical relationship, and (4) distance between the defender line and the goal line. The length was defined as the longitudinal distance between the player with ball possession and the nearest opponent from the goal line. The width was defined as the distance between the 2 more distant players, laterally. The numerical relationship was determined by the number of attacking players (players of the team with ball possession) and by the number of defensive players (players of the team without ball possession) within the area defined in terms of the width and length variables. Therefore, the defensive superiority was considered when the number of defenders was bigger than the number of attackers. Equality was identified when the number of defenders was the same as the number of attackers. In turn, offensive superiority occurred when the number of attackers was bigger than the number of defenders. Thus, if there were 7 attacking players against 6 defenders, for instance, the numerical relationship would be represented by $7 \times 6$. The distance between the defender line and the goal line was defined as the distance between the defensive player closer to the goal line and the goal line.

\section{Statistical analysis}

All data are presented as means \pm standard deviations. The chi-square independence test was used to evaluate the difference between the frequencies (in relation to the total number of frames) analysed in all numerical relationships and also in conditions of defensive superiority, equality, and offensive superiority. The level of significance was set at $p<0.05$. All statistical procedures were performed with the MATLAB software (MathWorks Inc., Natick, MA, USA).

\section{Ethical approval}

The research related to human use has been complied with all the relevant national regulations and institutional policies, has followed the tenets of the Declaration of Helsinki, and has been approved by the Ethics Committee of São Paulo State University.

\section{Results}

All offensive sequences presented the mean values and standard deviations of $24.59( \pm 13.40) \mathrm{m}$ for 


\section{HUMAN MOVEMENT}

N.M. de Souza et al., Space configuration in soccer matches

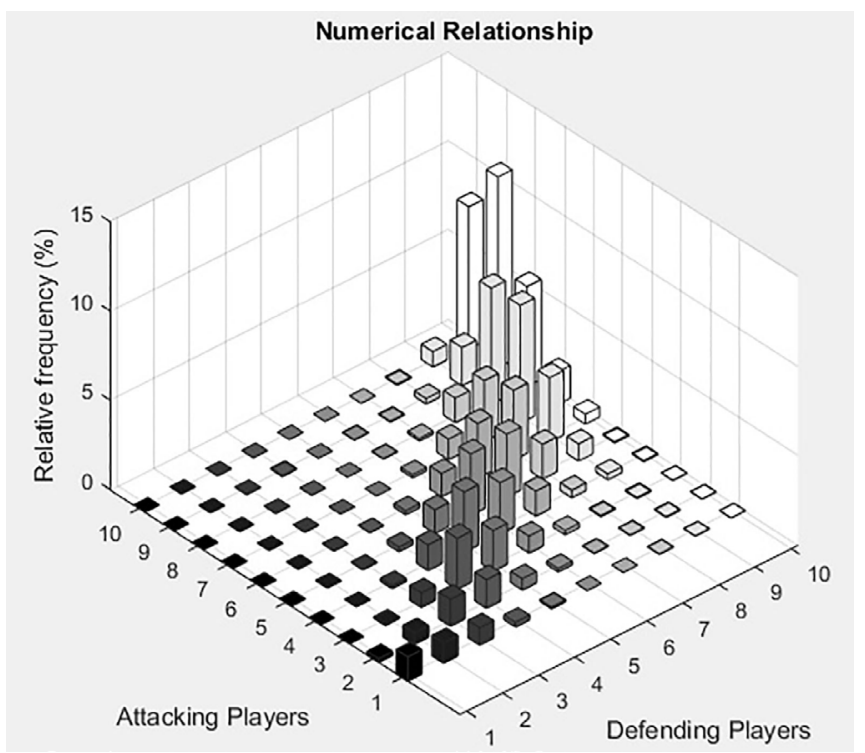

Figure 2. Relative frequency of all numerical relationship combinations among attackers and defenders during all studied matches

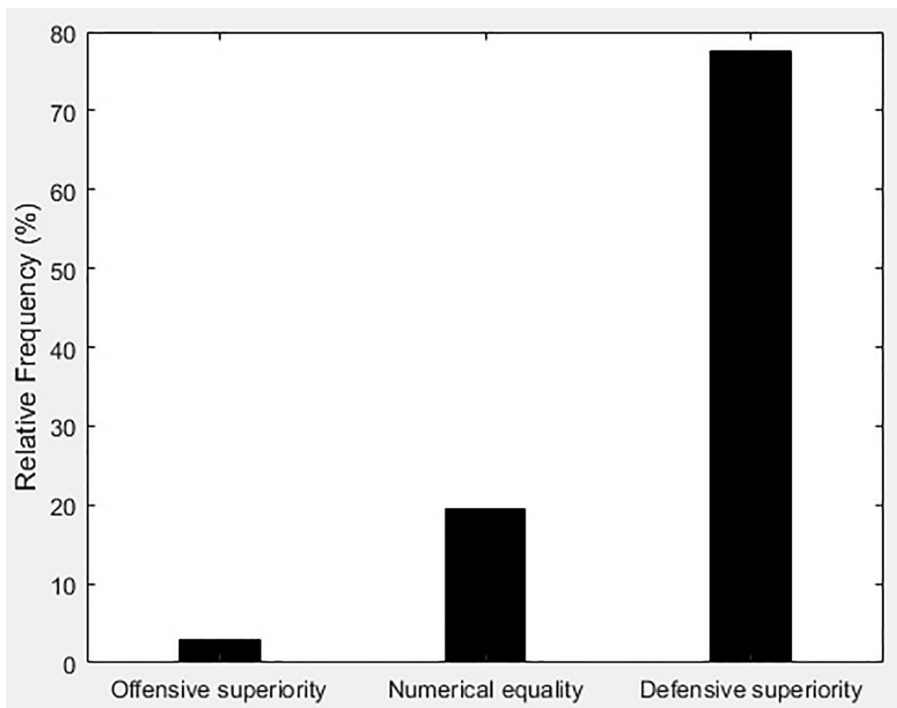

Figure 3. Relative frequency of offensive superiority, numerical equality, and defensive superiority during all studied matches

Table 1. Relative frequency (\%) of the numerical relationships among attackers and defenders during the matches

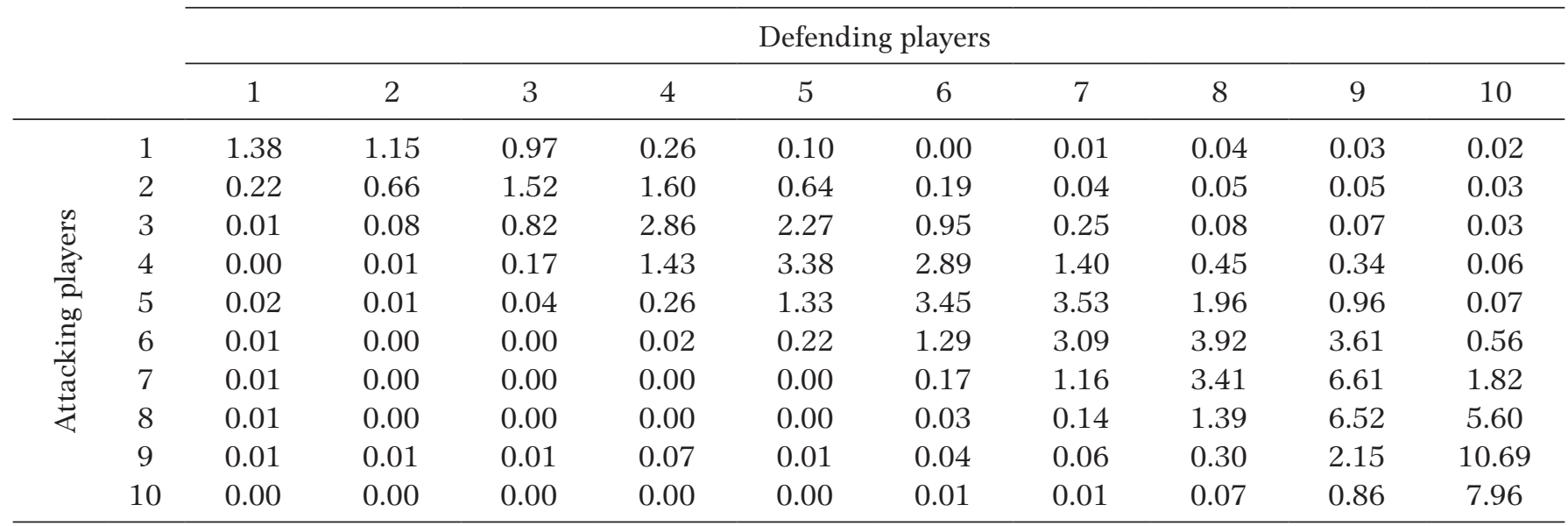

the length, 44.13 ( \pm 12.51) $\mathrm{m}$ for the width, and 29.19 $( \pm 11.40) \mathrm{m}$ for the distance to goal line. The relative frequency of all numerical relationships between attackers and defenders during the matches are presented in Figure 2 and Table 1. A significant difference was found between the groups $(p<0.001)$, indicating that larger numbers of participating players are more recurrent and that greater numbers of cases are close to numerical equality or little disadvantage.

Significant differences were observed between the relationships of superiority and equality during a match play, showing that defensive superiority is predominant in the game, followed by equality and, finally, offensive superiority $(p<0.001)$ (Figure 3 ).

The values for length ranged between $1.2( \pm 1.4)$ and 45.9 ( \pm 6.5) $\mathrm{m}$ (Table 2); width values ranged between
$9.5( \pm 0.1)$ and $54.0( \pm 7.0) \mathrm{m}$ (Table 3). The bigger the length and the width values, the more players are involved.

Table 4 presents the distance to the goal line during all the matches and the corresponding numerical relationships.

\section{Discussion}

This study aimed to analyse the most recurrent features of soccer attacking sequences regarding the effective space available, the numerical relationship, and the distance between the defensive line and the goal, with the rationale to provide coaches with insights to design soccer drills or SSGs during trainings in contexts similar to real match situations. Our 
Table 2. Mean (standard deviation) of the length $(\mathrm{m})$ for all numerical relationship combinations among attacking and defending players

\begin{tabular}{|c|c|c|c|c|c|c|c|c|c|c|c|}
\hline & \multicolumn{10}{|c|}{ Defending players } \\
\hline & & 1 & 2 & 3 & 4 & 5 & 6 & 7 & 8 & 9 & 10 \\
\hline \multirow{10}{*}{ 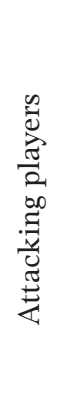 } & 1 & $1.2(1.4)$ & $3.4(3.3)$ & $14.2(11.7)$ & $6.5(5.4)$ & $9.4(3.5)$ & $15.7(0.5)$ & $19.3(1.7)$ & $21.3(2.2)$ & $23.8(1.9)$ & $23.1(2.5)$ \\
\hline & 2 & $2.6(2.2)$ & $4.3(2.9)$ & $8.1(7.3)$ & $9.0(5.4)$ & $12.3(5.1)$ & $13.4(4.9)$ & $16.8(4.4)$ & $22.2(1.6)$ & $22.8(1.7)$ & $24.5(1.7)$ \\
\hline & 3 & $1.8(1.0)$ & $5.9(3.7)$ & $8.8(5.0)$ & $10.6(6.0)$ & $12.5(6.1)$ & $14.0(5.6)$ & $14.3(6.9)$ & $21.5(6.3)$ & $22.3(2.2)$ & $24.9(1.6)$ \\
\hline & 4 & $1.0(0.1)$ & $7.1(2.9)$ & $10.4(6.2)$ & $11.4(6.9)$ & $13.1(5.7)$ & $15.6(6.4)$ & $16.9(5.1)$ & $17.5(5.7)$ & $20.3(4.7)$ & $30.1(1.9)$ \\
\hline & 5 & $1.4(0.7)$ & $2.7(0.4)$ & $7.0(2.8)$ & $14.0(8.1)$ & $16.0(6.8)$ & $17.1(6.7)$ & $19.2(6.4)$ & $19.3(5.7)$ & $20.8(4.4)$ & $23.0(2.4)$ \\
\hline & 6 & $4.1(0.7)$ & - & $2.5(0.0)$ & $22.6(17.8)$ & $17.7(8.0)$ & $23.1(8.0)$ & $22.5(7.2)$ & $22.1(5.9)$ & $22.3(5.3)$ & $28.1(6.2)$ \\
\hline & 7 & $6.7(0.8)$ & - & - & - & - & $25.5(7.9)$ & $26.0(9.3)$ & $26.1(7.6)$ & $25.1(5.6)$ & $27.7(5.0)$ \\
\hline & 8 & $9.5(0.8)$ & - & - & - & - & $33.8(9.1)$ & $29(10.2)$ & $31.9(7.9)$ & $28.8(6.7)$ & $31.0(5.2)$ \\
\hline & 9 & $12.2(0.8)$ & $13.9(0.3)$ & $15.5(0.6)$ & $23.9(4)$ & $32.3(0.5)$ & $35.1(3.2)$ & $42.3(8.2)$ & $39.5(6.5)$ & $35.5(8.3)$ & $35.6(5.3)$ \\
\hline & 10 & - & - & - & - & - & $30.0(0.6)$ & $31.9(0.5)$ & $41.8(4.0)$ & $45.9(6.5)$ & $43.2(7.1)$ \\
\hline
\end{tabular}

Table 3. Mean (standard deviation) of the width $(\mathrm{m})$ for all numerical relationship combinations among attacking and defending players

\begin{tabular}{|c|c|c|c|c|c|c|c|c|c|c|c|}
\hline & & \multicolumn{10}{|c|}{ Defending players } \\
\hline & & 1 & 2 & 3 & 4 & 5 & 6 & 7 & 8 & 9 & 10 \\
\hline \multirow{10}{*}{ 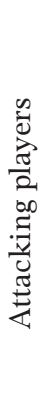 } & 1 & $13.0(10.6)$ & $21.0(10.8)$ & $20.9(7.8)$ & $30.9(7.5)$ & $31.3(3.0)$ & $24.9(0.3)$ & $25.5(1.2)$ & $32.6(6.8)$ & $31.4(3.5)$ & $29.2(5.2)$ \\
\hline & 2 & $25.4(11.0)$ & $25.0(9.1)$ & $26.2(8.2)$ & $32.7(8.6)$ & $36.8(8.3)$ & $39.9(10.4)$ & $32.3(5.8)$ & $31.8(5.7)$ & $33.9(3.0)$ & $32.7(4.6)$ \\
\hline & 3 & $25.2(10.7)$ & $31.4(6.4)$ & $32.3(8.9)$ & $34.2(9.2)$ & $36.3(8.9)$ & $38.8(8.2)$ & $38.8(7.5)$ & $34.6(8.8)$ & $37.5(9.1)$ & $34.9(5.1)$ \\
\hline & 4 & $16.1(3.3)$ & $31.4(8.6)$ & $32.8(5.5)$ & $37.2(8.5)$ & $38.4(8.9)$ & $38.3(8.5)$ & $41.7(7.3)$ & $42.3(5.8)$ & $42.6(6.2)$ & $37.3(4.5)$ \\
\hline & 5 & $14.5(5.0)$ & $9.5(0.1)$ & $17.0(12.6)$ & $38.0(8.5)$ & $41.9(8.7)$ & $41.9(8.3)$ & $43.6(7.7)$ & $44.4(7.5)$ & $44.6(6.8)$ & $43.1(6.2)$ \\
\hline & 6 & $20.9(0.3)$ & - & $28.6(0.2)$ & $35.0(9.1)$ & $45.3(11.0)$ & $44.2(9.0)$ & $45.0(7.9)$ & $46.3(6.9)$ & $46.8(7.2)$ & $45.9(7.6)$ \\
\hline & 7 & $21.6(0.3)$ & - & - & - & - & $43.8(6.6)$ & $46.6(8.3)$ & $46.9(7.7)$ & $48.7(6.9)$ & $49.5(7.2)$ \\
\hline & 8 & $23.0(0.5)$ & - & - & - & - & $38.7(7.1)$ & $41.9(10.5)$ & $49.0(9.3)$ & $50.9(7.0)$ & $52.6(6.7)$ \\
\hline & 9 & $24.8(0.5)$ & $25.8(0.2)$ & $27.1(0.6)$ & $32.1(1.6)$ & $35.6(0.3)$ & $37.0(1.2)$ & $39.5(4.4)$ & $46.0(8.2)$ & $50.4(8.3)$ & $54.0(7.0)$ \\
\hline & 10 & - & - & - & - & - & $35.5(0.1)$ & $35.3(0.2)$ & $42.4(4.7)$ & $48.4(8.9)$ & $51.9(7.4)$ \\
\hline
\end{tabular}

Table 4. Mean (standard deviation) of distance between the last defender and the goal line for all numerical relationship combinations among attacking and defending players

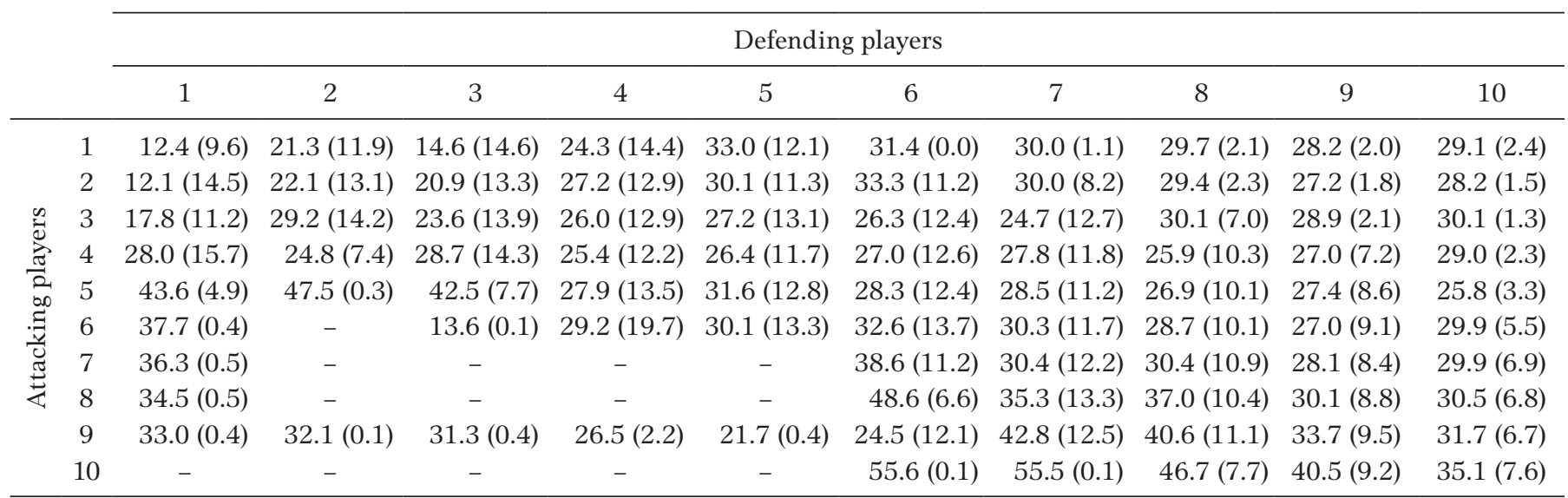

results showed a prevalence of large numbers of players involved in the attacking sequences, such as $10 \times$ $10,9 \times 10,8 \times 10,8 \times 9$, and $7 \times 9$ (Figure 2$)$. However, studies have presented that the most common SSG programs involve fewer players [5, 12]. Although the researchers demonstrated the effectiveness of such trainings in changing the players' physical and physiological fitness, additional research is necessary to investigate the influence of SSGs with a greater number of players, which are more similar in terms of running, sprinting, loading, and positional roles to an official match [7, 22]. 
N.M. de Souza et al., Space configuration in soccer matches

Our findings presented the length and width values considering all the players in front of the one with ball possession. This offers an insight into real situations that players deal with during a match, regarding the available space and number of teammates and opponents for decision-making. Literature studies have presented a great range of effective playing space in different games. For instance, SSGs of $5 \times 5$ have been reported in spaces ranging between 28 and $62 \mathrm{~m}$ for length, and 14 and $45 \mathrm{~m}$ for width [1, 6]. However, for this numerical relationship $(5 \times 5)$, the space configuration found in our results was $16.0( \pm 6.8) \mathrm{m}$ of length and $41.9( \pm 8.7) \mathrm{m}$ of width. Additionally, most studies $[1,5,12,14]$ reported length values greater than the width ones, the opposite of what really happens during a match (Tables 2 and 3). This outcome suggests coaches to review the space and numerical relationship configuration if they expect to better explore game simulations of real situations.

Fradua et al. [14] proposed a design of game space derived from official matches. The researchers computed IPA on the basis of the ball position and used that proportion for all possible SSGs. Although this proposal also simulates real match situations, it assumes that the area per player is always regular during soccer games. On the other hand, with IPA calculated in accordance with the length and width values of Tables 2 and 3, our findings show that when there is a $10 \times 10$ numerical relationship among attackers and defenders, IPA equals approximately $112 \mathrm{~m}^{2}$. However, in $7 \times 7$ situations, for example, IPA decreases to $87 \mathrm{~m}^{2}$. This outcome emphasizes the importance of considering a different space configuration for each numerical relationship, once it is expected that decision-making strategies during situations with more players involved in smaller areas are more complex because the players have restricted space and, consequently, restricted time to make decisions and perform actions [6].

The present results provide information that can assist coaches to define specific designs of SSGs, considering that there is an additional space between the last defender and the goal line. Therefore, players must invade the space to perform a shot to goal. Similarly, previous studies reported that the distance between the defender and goal line changed depending on the ball position [13-15]. Additionally, our findings showed that the distance changed depending on the numerical relationship, which is important information to be taken into account in training drills.

Figure 3 presents the difference in the relative frequency of situations with defensive superiority (when

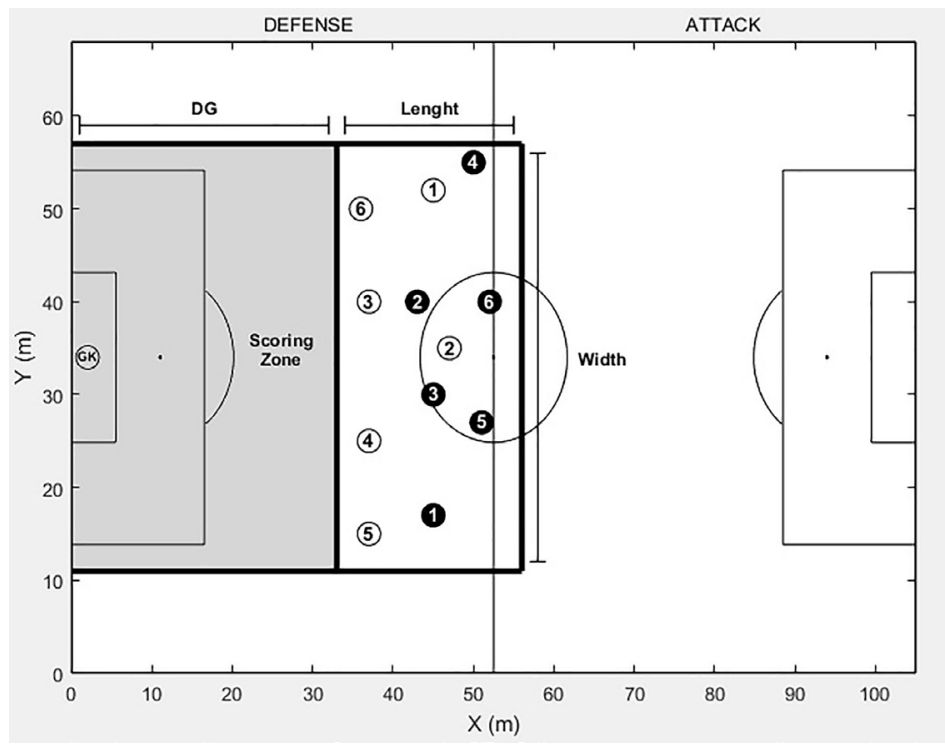

DG - distance to goal line, GK - goalkeeper

Figure 4. Example of a practical recommendation for $6 \times 6$ games in accordance with DG, length, and width

the number of defenders is bigger than the number of attackers), equality (when the number of defenders and of attackers is the same), and offensive superiority (when the number of attackers is bigger than the number of defenders). Our results indicated greater values for defensive superiority, considerably different from those observed in literature studies that have focused on evaluating games with numerical equality $[1,5,12,14]$. On the other hand, Práxedes et al. [9] showed that a training program using numerical superiority was better to improve the decision making in U12 players than a numerical equality program. Therefore, further studies may investigate numerical inferiority/superiority in accordance with the space configuration reported in the present study and the consequences in physical, technical, and tactical demands of the match. Thus, coaches can create and program trainings with different levels of complexity, increasing players' decision-making skills to deal with real match situations.

As for practical recommendations of our paper, coaches may create, for instance, $6 \times 6$ SSGs with the spaces presented in the study: about $23 \mathrm{~m}$ in length (Table 2) and $44 \mathrm{~m}$ in width (Table 3), with the objective of motivating players to invade the space; also, they may use the distance between the defensive line and goal line close to $33 \mathrm{~m}$ (Table 4) if the purpose of the game is to score a goal after the invasion (Figure 4). 


\section{Conclusions}

The study presented the most recurrent characteristics of soccer attacking sequences considering the numerical relationship, the effective space available, and the distance between the defensive line and the goal. We demonstrated that the most recurrent attacking sequences had a large number of players involved. The length, width, and distance between the defender and the goal line are influenced by the numerical relationship and usually width is greater than length. Regarding the numerical relationship between defenders and attacking players, our study identified more situations of defensive superiority, followed by equality contexts. These characteristics can support coaches to design SSGs during trainings in order to improve players' skills to deal with what happens in real situations during a soccer match. The limitations of the study are mainly related to data acquisition. Because of the small sample size, generalization of conclusions drawn could be limited and further studies should incorporate a higher sample of matches. However, we emphasize that the high-cost of real time technologies to collect player position as a function of time, like the Global Positioning System or Local Positioning Measurement, is still a restriction for the great part of researchers and sports staff. Instead, an accurate and low-cost video-based system was used, which, on the other hand, increased the processing time substantially.

\section{Acknowledgements}

The authors are grateful to National Council for Scientific and Technological Development (CNPq) (grants \#307560/2016-3 and \#446548/2014-6) and the São Paulo Research Foundation (FAPESP) (grants \#2016/ 50250-1 and \#2017/20945-0). This study was financed in part by the Coordenação de Aperfeiçoamento de Pessoal de Nível Superior (CAPES), Brazil, finance code 001 .

\section{Disclosure statement}

No author has any financial interest or received any financial benefit from this research.

\section{Conflict of interest}

The authors state no conflict of interest.

\section{References}

1. Hill-Haas SV, Dawson B, Impellizzeri FM, Coutts AJ. Physiology of small-sided games training in football: a systematic review. Sports Med. 2011;41(3):199-220; doi: 10.2165/11539740-000000000-00000.

2. Alves G, Clemente FM, Malico Sousa P, Pinheiro V, dos Santos FJL. How and why do soccer coaches use small-sided games in the training process? Hum Mov. 2017;18(5):117-124; doi: 10.5114/hm.2017.73624.

3. Langendam L, Linden CMI, Clemente FM. Difference in training load and technical actions during smallsided games in junior and senior soccer players. Hum Mov. 2017;18(5):146-156; doi:10.5114/hm.2017.73623.

4. González-Víllora S, Clemente FM, Martins FML, Pastor-Vicedo JC. Effects of regular and conditioned smallsided games on young football players' heart rate responses, technical performance, and network structure. Hum Mov. 2017;18(5):135-145; doi: 10.5114/hm.2017. 73618

5. Halouani J, Chtourou H, Gabbett T, Chaouachi A, Chamari K. Small-sided games in team sports training: a brief review. J Strength Cond Res. 2014;28(12):35943618; doi: 10.1519/JSC.0000000000000564.

6. Ometto L, Vasconcellos FVA, Cunha FA, Teoldo I, Souza CRB, Dutra MB, et al. How manipulating task constraints in small-sided and conditioned games shapes emergence of individual and collective tactical behaviours in football: a systematic review. Int J Sports Sci Coach. 2018;13(6):1200-1214; doi: 10.1177/17479541 18769183.

7. Clemente FM, Sarmento H, Rabbani A, Van Der Linden C, Kargarfard M, Costa IT. Variations of external load variables between medium- and large-sided soccer games in professional players. Res Sports Med. 2019; 27(1):50-59; doi: 10.1080/15438627.2018.1511560.

8. Olthof SBH, Frencken WGP, Lemmink KAMP. Matchderived relative pitch area changes the physical and team tactical performance of elite soccer players in smallsided soccer games. J Sports Sci. 2018;36(14):15571563; doi: 10.1080/02640414.2017.1403412.

9. Práxedes A, Moreno A, Gil-Arias A, Claver F, Del Villar F. The effect of small-sided games with different levels of opposition on the tactical behaviour of young footballers with different levels of sport expertise. PLoS One. 2018;13(1):e0190157; doi: 10.1371/journal.pone.0190157.

10. Travassos B, Gonçalves B, Marcelino R, Monteiro R, Sampaio J. How perceiving additional targets modifies teams' tactical behavior during football small-sided games. Hum Mov Sci. 2014;38:241-250; doi: 10.1016/ j.humov.2014.10.005.

11. Casamichana D, Suarez-Arrones L, Castellano J, RománQuintana JS. Effect of number of touches and exercise duration on the kinematic profile and heart rate response during small-sided games in soccer. J Hum Kinet. 2014;41:113-123; doi: 10.2478/hukin-2014-0039.

12. Hammami A, Gabbett TJ, Slimani M, Bouhlel E. Does small-sided games training improve physical fitness and team-sport-specific skills? A systematic review and meta-analysis. J Sports Med Phys Fitness. 2018;58(10): 1446-1455; doi: 10.23736/S0022-4707.17.07420-5. 


\section{HUMAN MOVEMENT}

N.M. de Souza et al., Space configuration in soccer matches

13. Castellano J, Álvarez-Pastor D, Blanco-Villaseñor Á. Analyzing the space for interaction in soccer [in Spanish]. Rev Psicol Deporte. 2013;22(2):437-446.

14. Fradua L, Zubillaga A, Caro O, Iván Fernández-García A, Ruiz-Ruiz C, Tenga A. Designing small-sided games for training tactical aspects in soccer: extrapolating pitch sizes from full-size professional matches. J Sports Sci. 2013;31(6):573-581; doi: 10.1080/02640414.2012. 746722 .

15. Zubillaga A, Gabbett TJ, Fradua L, Ruiz-Ruiz C, Caro Ó, Ervilla R. Influence of ball position on playing space in Spanish elite women's football match-play. Int J Sports Sci Coach. 2013;8(4):713-722; doi: 10.1260/1747-9541. 8.4.713.

16. Gonçalves B, Folgado H, Coutinho D, Marcelino R, Wong D, Leite N, et al. Changes in effective playing space when considering sub-groups of 3 to 10 players in professional soccer matches. J Hum Kinet. 2018;62:145155; doi: 10.1515/hukin-2017-0166.

17. Caro O, Fradua L, Zubillaga A, Fernandez-Navarro J. Analysis of small game areas of 4vs4 and 7vs7 in Spanish professional football. In: Proceedings of the 2nd International Congress on Sports Sciences Research and Technology Support. 2014:231-235; doi: 10.5220/000 5191202310235.

18. Clemente FM, Couceiro MS, Martins FML, Mendes RS, Figueiredo AJ. Soccer team's tactical behaviour: measuring territorial domain. Proc Inst Mech Eng P J Sport Eng Technol. 2015;229(1):58-66; doi: 10.1177/17543371 14547064.

19. Vilar L, Araújo D, Davids K, Bar-Yam Y. Science of winning soccer: emergent pattern-forming dynamics in association football. J Syst Sci Complex. 2013;26(1): 73-84; doi: 10.1007/s11424-013-2286-z.

20. Abdel-Aziz YI, Karara HM. Direct linear transformation from comparator coordinates into object space coordinates in close-range photogrammetry. Photogramm Eng Remote Sensing. 2015;81(2):103-107; doi: 10.14358/ PERS.81.2.103.

21. Moura FA, Martins LE, Anido Rde O, de Barros RM, Cunha SA. Quantitative analysis of Brazilian football players' organisation on the pitch. Sports Biomech. 2012; 11(1):85-96; doi: 10.1080/14763141.2011.637123.

22. Lacome M, Simpson BM, Cholley Y, Lambert P, Buchheit M. Small-sided games in elite soccer: does one size fit all? Int J Sports Physiol Perform. 2018;13(5):568576; doi: 10.1123/ijspp.2017-0214. 